\title{
Cartas de um sincero fingidor: o discurso esotérico na correspondência de Fernando Pessoa
}

\section{Letters by a sincere pretender: the esoteric discourse in Fernando Pessoa's letters}

Fernando de Moraes Gebra ${ }^{1}$

Graduado em Letras Português/Francês na Universidade Estadual Paulista (UNESP) (2002); Mestre em Letras, area de Estudos Literários, pela Universidade Estadua de Londrina (UEL) (2003); Doutor em Letras, na área de Estudos Literários, pela Paná (UFPR)
RESUMO: 0 presente artigo centra-se em cartas que Fernando Pessoa (1888-1935) escreveu de 1913 a 1916, período marcado pelas suas crises intelectuais e esotéricas, e também pela elaboração de projetos culturais necessários por arrancar da estagnação cultural a acanhada capital portuguesa. É desse período importantes cartas marcadas pela sinceridade e pela confissão a destinatários como Armando Côrtes-Rodrigues (1891-1971) e Mário de Sá-Carneiro (1890-1916), ao contrário do que ocorre nos anos posteriores a 1927, quando Pessoa escreve aos membros da revista Presença, optando por manter informações no plano do segredo. É o que ocorre na conhecida carta a Adolfo Casais Monteiro, escrita em 13 de janeiro de 1935, em que nega pertencer a alguma ordem secreta, ao contrário do que se encontra em um escrito autobiográfico, não publicado em vida. Tomo, como principal referencial teórico para o estudo de cartas, as propostas de Crabbé Rocha, no livro A epistolografia em Portugal. Em muitas das cartas de Pessoa, encontram-se transcrições de poemas. Dessa forma, o estudo das cartas de Pessoa permite a compreensão de aspectos simbólicos e metafóricos contidos nos poemas. Para a análise do discurso esotérico presente nas cartas de Pessoa, parto dos estudos de Manuela Parreira da Silva, Dalila Pereira da Costa e Yvette Centeno.

Palavras-chave: Fernando Pessoa; Epistolografia; Discurso esotérico.

ABSTRACT: The present article is focused in letters that Fernando Pessoa (1888-1935) wrote from 1913 to 1916, a period marked by his intelectual and esoteric crisis, and also by the production of cultural projects needed to take away the cultural stagnation from the timid Portuguese capitol. Important letters are from this period, marked by sincerity and confession to the addresses, as Armando Côrtes-Rodrigues (1891-1971) and Mário de Sá-Carneiro (1890-1916), unlike of what happens in the next years after 1927, when Pessoa writes to the members from the Presença magazine, choosing to keep informations as a secret. It's what happens at the knowing letter to Adolfo Casais Monteiro, wrote in January 13th, 1935, in which he denies to belong to some secret order, unlike it's found in a autobiographical write, not published during his lifetime. I take, as main theoretical frame of reference to the study of letters, Crabbé Rocha's proposals, in the book A epistolografia em Portugal. In many Pessoa's letters poems transcripts are found. This way, the study about Pessoa's letters allows to understand the symbolic and metaphoric aspects contained in the poems. To the analysis about the esoteric speech contained in Pessoa's letters, I use Manuela Parreira da Silva, Dalila Pereira da Costa e Yvette Centeno's studies.

KEYwoRDS: Fernando Pessoa; Ephistolography; Esoteric discourse. 


\section{Introdução}

A tratar da epistolografia como gênero do discurso, é preciso esclarecer que se trata de um gênero de fronteira com o diário, o romance, o ensaio, considerando o conteúdo e os meios expressivos de elaboração da carta. No conjunto de cartas de um escritor, é possível perceber em cada peça uma imagem isolada e estática, que posta em conjunto com outras peças de igual natureza, adquirem um movimento típico do cinema, como sustenta Crabbée Rocha: "Só uma enorme quantidade de imagens dessa natureza nos permitirá reconstituir o filme movimentado duma vida, ou o - mais subtil - dum espírito ou duma alma" (1965, p. 17). Nesse sentido, o estudo da produção epistolográfica de um autor permite-nos a compreensão do contexto histórico-cultural em que escreveu, a iluminação de pontos difusos da sua obra e a revelação de aspectos que recobrem a intimidade do escritor, uma vez que nesse gênero se costuma escrever sem muitos rebuços.

No entender de Crabbée Rocha, o valor biográfico do gênero epistolar é fácil de demonstrar, uma vez que "é a carta uma revelação da personalidade íntima no que tem de mais superficial como de mais profundo" (1965, p. 24). A pudicícia formalista que impregnou os estudos literários nas décadas de 1950 e 1960, com os formalistas e estruturalistas, fez com que se excluíssem do âmbito da análise literária os aspectos biográficos do autor, pois para essas correntes críticas, importava ressaltar apenas os elementos de fatura do texto literário. É célebre uma frase de Algirdas Julien Greimas de que "fora do texto não há salvação". Antonio Candido, embora reconheça a importância de métodos que priorizam a análise imanentista do texto literário, propõe um método de "interpretação dialeticamente íntegra" (1973, p. 4), em que os elementos externos ao texto (inclusive os biográficos) servem à medida que são incorporados à sua economia interna. Visto por esse ângulo, se relevantes para a compreensão da linguagem poética, os elementos biográficos devem ser considerados, como é o caso das constantes referências esotéricas feitas por Fernando Pessoa no seu conjunto epistolar, que serão discutidas neste trabalho.

\section{0 gênero epistolar e o "diálogo numa alma"}

O livro A epistolografia em Portugal, de Crabbé Rocha, contem uma recolha e seleção de cartas de escritores encetadas em uma antologia composta de dois estudos críticos, abrangendo um recorte histórico que vai do período do Infante D. Pedro (1392-1449) até Fernando Pessoa (1888-1935), passando por importantes escritores como: Camões, Francisco Rodrigues Lobo, Padre António Vieira, Almeida Garrett, Alexandre Herculano, Camilo Castelo Branco, João de Deus, Júlio Diniz, Antero de Quental, Teófilo Braga, Oliveira Martins, Eça de Queirós, Gomes Leal, Guerra Junqueiro, Cesário Verde, António Nobre, Manuel Laranjeira, Teixeira de Pascoaes, Mário de Sá-Carneiro, Florbela Espanca, dentre outros. Trata-se, pois, de uma pesquisa minuciosa, na qual se fez relevante a escolha de cartas significativas para compor a seleta, além de um extenuante tratamento dos dados, resultando nos estudos inicial e conclusivo da obra. Na época de publicação dessa importante obra de epistolografia (1965), havia em Portugal poucos trabalhos teóricos sobre esse gênero do discurso: "Em compensação, não faltam, a seu propósito, referências avulsas, especialmente pelo que diz respeito ao endereço da missiva, ao tratamento adequado, à disposição gráfica do texto" (1965, p. 32).

Dos principais teorizadores desse gênero em Portugal, citados por Crabbé Rocha, destacam-se: Francisco Rodrigues Lobo (1579?-1621) e Cândido Lusitano. Do primeiro, destaca-se a divisão das cartas em três grupos: "cartas familiares, cartas de amigos para amigos [...] e cartas sobre matéria do governo da república e matérias divinas" (ROCHA, 1965, p. 33). Rodrigues Lobo é apontado pela autora como "o primeiro teorizador da arte 
de escrever cartas" (1965, p. 32) e, de certa forma, é ele quem estabelece as características e propriedades desse gênero discursivo: "brevidade sem enfeite, clareza sem rodeios e propriedade sem metáforas nem translações" (1965, p. 33). É preciso, pois, relativizar esses aspectos, pois Rodrigues Lobo viveu no período clássico, em que as regras e as etiquetas cortesãs deveriam ser respeitadas, além das noções de equilíbrio e racionalidade desse estilo de época. Como se verá neste trabalho, a correspondência de Fernando Pessoa apresenta metáforas e símbolos, já que o discurso literário presente nessas missivas se cruza com o discurso esotérico, marcado por analogias e hermetismo.

De maneira mais didática que os diálogos de Rodrigues Lobo, encontrase o Secretário português compendiosamente instruído no modo de escrever cartas, publicado em 1745 por Cândido Lusitano. Além de ter coligido para principiantes o que foi escrito em diversas línguas sobre o gênero epistolar, o autor aponta simetricamente, seguindo os pressupostos da estética neoclássica, "as 5 virtudes (segredo, erudição, generalidade, reflexão, eloquência) e os 5 vícios (demora, prolixidade, aspereza, ignorância, escuridade)" (ROCHA, 1965, p.34). Com relação à virtude do segredo, ao tratar do aspecto do destinatário das cartas, Crabbé Rocha ressalta que elas se dirigem, normalmente, "a um leitor vivo e único":

A meio caminho, pois, entre o diarista que fala para si, e o criador que fala para o infinito público anónimo, o epistológrafo pratica uma escolha, uma eleição, que condiciona incontestavelmente o texto que vai escrever, quer no plano da franqueza, quer no do estilo. A si próprio, o diarista pode confessar o inconfessável; o artista elabora, corta, compõe, sublima a sua verdade; o epistológrafo, esse, requinta o que tem para dizer conforme o destinatário a quem confia. $(1965$, p. 18$)$

Tanto o diário como a carta são gêneros relacionados a uma escrita autobiográfica, confirmando "o alto valor atribuído ao eu que a subscreve" (idem, p. 21). A escrita do eu parece ser o ponto de convergência dos gêneros epistolar e ensaístico. Teóricos do ensaio como Theodor Adorno, Pedro Chamizo Domínguez e Arturo Casas confirmam o ensaio como a escrita do eu, situando essa modalidade discursiva em contraposição ao discurso científico. Adorno afirma que "el ensayo no obedece la regla del juego de la ciencia y la teoría organizadas” (2003, p. 19), evitando uma ordem conceitual fixa. Chamizo Domínguez situa o ensaio como gênero que serve para uma busca de uma verdade situada no futuro, não uma verdade já preestabelecida, mas algo que ainda se busca, algo incerto, desconhecido, diferente do discurso científico, encontrado nos manuais e nos livros-texto, em que a verdade aparece como algo dado e irrefutável. Opera-se, assim, a crítica a um paradigma dado como imutável. E, por fim, Arturo Casas, após citar os posicionamentos de grandes teóricos do ensaio como Walter Mignolo, José Luis Gómez-Martínez, Theodor Adorno e Georg Lukács, confirma o ensaio como forma crítica que reage contra a forma de conhecimento científica, a qual recorre sempre a provas em seu discurso (1999, p. 2).

Como aponta Candido Lusitano (1719-1773), a reflexão constitui uma das cinco virtudes do gênero epistolar, o que corrobora para minha proposta de leitura das cartas de Fernando Pessoa em aproximação ao discurso ensaístico acerca de grandes questões existenciais. Por um lado, encontramse cartas nas quais o enunciador se coloca numa postura professoral com relação ao enunciatário. Por outro lado, há discursos epistolares que buscam uma verdade situada no futuro, que se constrói na relação com o outro, com o enunciatário que irá responder a carta em questão, em um interminável diálogo, tal como concebido por Chamizo Dominguez ao equiparar o ensaio com os diálogos filosóficos.

Para esse autor, o ensaio moderno, tal como concebido por Montaigne, se aparenta ao diálogo filosófico proposto por Sócrates, na busca de uma verdade situada no futuro, não uma verdade já sabida e inquestionável, mas 
sim uma verdade que é, ao mesmo tempo, ignorância, "entendida no como falta absoluta de conocimiento sino como reconocimiento de los limites de lo sabido" (1999, p. 26). Tanto no ensaio como nas cartas ensaísticas, o eu não apresenta certezas, apenas levanta hipóteses, estabelecendo "una relación horizontal entre el autor y el lector como la que tenían los participantes en los diálogos platónicos y como la que suelen tener los amigos"(1999, p. 24).

É o caso das cartas trocadas por Mário de Sá-Carneiro e Fernando Pessoa. "Éramos como um diálogo numa alma", referiu-se Pessoa ao autor de A confissão de Lúcio, em um poema intitulado "Sá-Carneiro". Embora SáCarneiro solicite com afinco as opiniões do amigo acerca de seus poemas, muitos deles transcritos nas cartas, também opina sobre a produção poética pessoana, o que me levaria a aproximar essas missivas do gênero ensaístico, pois, "[...] em muitos casos, a carta transmite 'novidades' ainda mal assimiladas, escritas na altura em que foram experimentadas ou conhecidas. E daí resulta, evidentemente uma falta de perspectiva e maturação" (ROCHA, 1965, p. 17). A constante troca de cartas entre Pessoa e Sá-Carneiro permite uma constante reelaboração de seus projetos e obras, já que o diálogo com o outro possibilita o reconhecimento dos limites do sabido, tal como sustenta Chamizo Domínguez sobre o gênero ensaístico.

Quando se estudam as cartas escritas por Sá-Carneiro a Fernando Pessoa, costuma-se ter acesso a 114 cartas publicadas pelas Edições Ática, de Lisboa, e a 102 textos (cartas, postais e telegramas) publicados por Arnaldo Saraiva no volume intitulado Correspondência inédita de Mário de Sá-Carneiro a Fernando Pessoa. Entretanto, das cartas escritas por Pessoa ao seu maior amigo, encontram-se apenas três no espólio da Biblioteca Nacional e publicadas em edições como as da Assírio \& Alvim, em Portugal, e Companhia das Letras, no Brasil. Essas cartas foram escritas em 6 de dezembro de 1915, 14 de março e 26 de abril de 1916. 0 restante das muitas cartas enviadas por Pessoa para Paris, onde residia Mário de
Sá-Carneiro, perderam-se após o suicídio deste último no Hotel Nice, em 26 de abril de 1916, data em que Fernando Pessoa (coincidentemente?) lhe escrevia a última carta que certamente foi devolvida ao remetente por conta do falecimento do destinatário. Sobre o desparecimento das cartas, comenta Dionísio Vila Maior:

Note-se que a maior parte das cartas que Pessoa dirigiu a Sá-Carneiro (que estavam numa mala deixada no então Hotel Nice, onde Sá-Carneiro se suicidou em 1916) se perdeu, em circunstâncias que ainda estão por esclarecer. No espólio de Fernando Pessoa, foram, entretanto, encontradas 114 cartas enviadas por Sá-Carneiro ao seu principal companheiro na aventura do Orpheu, publicadas em dois volumes pela Ática. (1996, p. 69)

Além das três missivas que Pessoa escreveu a Sá-Carneiro, encontra-se um rascunho de carta sem data, que Manuela Parreira da Silva conjetura ser de 1913, como é possível perceber nas notas da organizadora do volume de cartas de Fernando Pessoa de 1905 a 1922:

[...] pode, presumivelmente, situar-se em 1913, pois é possível que Pessoa se refira ao artigo intitulado 'O Teatro-Arte'(jornal $O$ Rebate, de 28 de novembro desse ano). Neste artigo, Sá-Carneiro critica fortemente alguns dos visados também nesta carta: João de Barros, Joaquim Manso, Júlio Dantas. (1999a, p. 425)

As outras três cartas que Pessoa escreveu a Sá-Carneiro não se perderam pelo fato de que o autor de Mensagem costumava copiar algumas de suas missivas antes de enviá-las aos destinatários, como deixa claro no post escriptum da carta de 14 de março de 1916: "P.S - Escrevi esta carta de um jacto. Relendo-a, vejo que, decididamente, a copiarei amanhã, antes de lha mandar" (PESSOA, 1999, p. 211). Ou, ainda, no corpo da carta, demonstra a intenção de fazer um uso literário desse texto em um dos fragmentos do Livro do Desassossego: 
Pode ser que se não deitar hoje esta carta no correio amanhã, relendo-a, me demore a copiá-la à máquina, para inserir frases e esgares dela no Livro do Desassossego. Mas isso nada roubará à sinceridade com que a escrevo, nem à dolorosa inevitabilidade com que a sinto. (1999a, p. 211)

Extremamente presente na poesia de Fernando Pessoa, o discurso esotérico também se apresenta em muitas de suas cartas. Crabbé Rocha sustenta que a produção missiva do "poeta fingidor" refere-se "predominantemente à actividade criadora de Pessoa, a projectos de revistas ou antologias, à compilação dos poemas de Sá-Carneiro e à planificação editorial das suas próprias produções" (1965, p. 403). Nesse sentido, a correspondência de Fernando Pessoa fornece um importante documento da trajetória histórica da geração de Orpheu e das relações que Fernando Pessoa estabelece entre discurso esotérico e discurso literário.

\section{A Revista Orpheu e o "ideal esotérico"}

O Primeiro Modernismo Português - ou Orfismo devido à presença de artistas ligados à Revista Orpheu - pode ser visto, conforme apontamento de Fernando Pessoa para uma possível entrevista (cf. VILA MAIOR, 1996, p. 67), como uma síntese de todos os movimentos literários modernos, uma arte complexa, resultado da intersecção de todas as artes do mundo, sendo, portanto, cosmopolita no tempo e no espaço. Além de pretender divulgar uma obra irreverente que chocasse a burguesia, os artistas órficos, em diálogo também com o Simbolismo e o Decadentismo, pretendiam estabelecer estreitas relações entre poesia e ocultismo, apontadas por Antonio Quadros (2000, p. 36).

Na introdução do primeiro número da Orpheu, Luís de Montalvor afirma que "Nossa pretensão é formar, em grupo ou ideia, um número escolhido de revelações em pensamento ou arte, que sobre este princípio aristocrático tenham em ORPHEU o seu ideal esotérico e bem nosso de nos sentirmos e conhecermo-nos" (1971, p. 11). O ideal esotérico órfico baseia-se no postulado do poeta Orpheu de que o ser humano se apresenta dividido em dois aspectos: o lado titânico e o divino. Assim, pela iniciação, o ser humano deve assumir sua condição conflituosa e monstruosa e purificá-la para que o elemento divino se cultive de forma mais significativa.

Caracterizada como uma revista órfica, não só no título, mas também nos propósitos e em muito do que nela foi publicado, a Orpheu assume, ao mesmo tempo, segundo Antonio Quadros, "o titanismo (a cisão, a desagregação, o tumulto, a treva) e a ascese purificadora dos iniciados (dionísica, divina)" (2000, p. 38). Tal como na poesia dos simbolistas franceses, a produção poética dos jovens de Orpheu apresenta relações entre o discurso literário e o discurso esotérico, na medida em que o poeta, ao realizar o seu trabalho artístico, pretende o domínio dos mistérios, tal como objetivavam os alquimistas. Tal posição é sustentada por Gaspar Simões, ao tratar da "simbólica mágica" (1950, p. 560), presentes na poesia de Arthur Rimbaud (1854-1891) e de Fernando Pessoa. Essa simbólica mágica articula-se na própria linguagem, fundada numa gramática psicológica, a fim de se realizar a perquirição dos estratos profundos do interior do sujeito (cf. MOISÉS, 1984, p. 9).

Além do aspecto da purificação, o grupo de Orpheu pretendia ligar Portugal às modernas vanguardas europeias e livrá-lo da estagnação em que se encontrava. Ao referir-se à vanguarda interseccionista na carta a Armando Côrtes-Rodrigues de 19 de janeiro de 1915, Fernando Pessoa sustenta que

Será talvez útil - penso - lançar essa corrente como corrente, mas não com fins meramente artísticos, mas, pensando esse ato a fundo, como uma série de ideias que urge atirar para a publicidade para que possam agir sobre o psiquismo nacional, que precisa ser trabalhado em todas as direções por novas correntes de ideias e emoções que nos arranquem à nossa estagnação. (1999a, p. 143) 
A concretização dessa "corrente como corrente", dessa "série de ideias que urge atirar para a publicidade" para agir sobre a mentalidade ainda provinciana da capital portuguesa, arrancando o público leitor da sua estagnação, acostumado que estava com o convencionalismo e o tradicionalismo de autores como Júlio Dantas (1876-1962), é anunciada a Côrtes-Rodrigues em carta de 19 de fevereiro de 1915:

Vai entrar imediatamente no prelo a nossa revista, Orpheu, de que é diretor em Portugal um poeta, Luís de Montalvor, amigo íntimo de Sá-Carneiro, e meu amigo também, e no Brasil, um dos mais interessantes e nossos dos poetas brasileiros de hoje, Ronald de Carvalho. (1999a, p. 150)

A composição da revista, como os colaboradores, a tiragem e as assinaturas são descritas ao mesmo Côrtes-Rodrigues em carta de 4 de março. Além de pedir a seu amigo que consiga assinaturas dos possíveis compradores da revista, salienta a importância da Orpheu, como ponte de passagem da alma lusitana para o futuro: "Temos que firmar esta revista, porque ela é a ponte por onde a nossa Alma passa para o futuro" (1999a, p. 158). Comenta também sobre suas colaborações na revista. Tratam-se dos poemas de Álvaro de Campos “Opiário" e "Ode triunfal” e do drama estático "O marinheiro", de Fernando Pessoa-ele mesmo.

Apesar de os exemplares do primeiro número da Orpheu terem sido esgotados, a imprensa portuguesa fez comentários desfavoráveis aos escritores órficos. Em 4 de abril de 1915, Fernando Pessoa escreve a CôrtesRodrigues sobre o esgotamento dos exemplares, sobre a possibilidade de se fazer uma segunda edição do primeiro número da revista. Pessoa acrescenta que "Somos o assunto do dia em Lisboa. Sem exagero lho digo. $O$ escândalo é enorme. Somos apontados na rua, e toda a gente - mesmo extraliterária - fala no Orpheu" (1999a, p. 163). Na carta de 19 de abril, também a CôrtesRodrigues, Pessoa revela uma atitude de deboche diante dos artigos que a imprensa escreveu sobre a revista Orpheu: "E não tenho tempo para tratar de reunir alguns, pelo menos, dos artigos que se têm escrito sobre o Orpheu, tenho pena de que não o possa fazer, porque v. havia de rir imenso com eles" (1999a, p. 164).

Orpheu passava por situação de desprezo e ameaça do público burguês, principalmente devido às produções "Manucure", de Sá-Carneiro, e "Ode marítima", de Álvaro de Campos, que foram classificadas de escandalosas, impertinentes e até de pornográficas. As críticas aos poetas de Orpheu foram tantas que, após a publicação do segundo número da revista, Fernando Pessoa, sob assinatura e estilo sensacionista do heterônimo de Álvaro de Campos, escreveu duas cartas ao jornal A capital. A carta de 6 de julho de 1915 é marcada por um discurso irônico; no entanto, considero mais significativa a de 4 de junho, devido aos comentários feitos sobre Literatura.

Na carta de 6 de junho, Álvaro de Campos afirma que, durante toda a história literária, os gênios foram incompreendidos, tratados como loucos ou parvos ou ainda como inimigos da pátria, da religião e da moralidade. Acentua a ignorância dos críticos portugueses quando eles consideraram a revista Orpheu cheia de poemas futuristas. Diz que apenas a "Ode triunfal" apresenta marcas de Futurismo no plano do conteúdo, mas não no plano da expressão. Conclui que em arte "a forma de realizar é que caracteriza e distingue as correntes e as escolas” (1999a, p. 166).

Nessa carta, encontra-se uma importante diferenciação entre o Futurismo e o Interseccionismo. Para Álvaro de Campos, o Futurismo é objetivo, dinâmico e marcado pela "eliminação, da arte, de tudo quanto é alma, quanto é sentimento, emoção, lirismo, subjetividade em suma. O Futurismo é dinâmico e analítico por excelência" (1999a, p. 166). Já o Interseccionismo, "(tal o nome do movimento português), é a subjetividade excessiva, a síntese levada ao máximo, o exagero da atitude estática” (1999a, p. 166). 
Como exemplo de produções Interseccionistas, cita a peça "O marinheiro" de Fernando Pessoa-ele mesmo, marcada por tédio, sonho e abstração, tal como nas demais obras dos poetas órficos.

Apesar da boa venda que os dois primeiros números da revista Orpheu tiveram, a contabilidade corria mal, o que fez com que o pai de Mário de Sá-Carneiro o dissuadisse da ideia de continuar com o financiamento da revista. Radicado em Paris, com problemas psicológicos, Sá-Carneiro acabou por se suicidar em 26 de abril de 1916. Após a morte de Sá-Carneiro, Fernando Pessoa tentou lançar o terceiro número da revista, perceptível em fragmento da carta escrita em 4 de setembro de 1916 a CôrtesRodrigues.

Vai sair Orpheu 3. É aí que, no fim do número, publico dois poemas ingleses meus, muito indecentes, e, portanto, impublicáveis em Inglaterra. Outra colaboração do número: Versos do Camilo Pessanha (a propósito: "não cite isto a ninguém"), versos inéditos do Sá-Carneiro, A Cena do Ódio do AlmadaNegreiros (que está actualmente homem de génio em absoluto, uma das grandes sensibilidades da literatura moderna), prosa do Albino de Meneses (não sei se v. conhece) e, talvez, do Carlos Parreira, e uma colaboração variada do meu velho e infeliz amigo Álvaro de Campos. (1999a, p. 222)

Apesar dos esforços de Fernando Pessoa em resgatar o projeto de Orpheu, não foi possível a publicação do terceiro número, aparecendo no lugar outra revista, de número único, a Centauro. Depois do desaparecimento de Orpheu, novas tentativas foram feitas para continuar sua proposta; no entanto, não com a mesma energia do grupo. É o caso da revista Portugal Futurista de 1917, que só teve um único número. É o caso também da revista Contemporânea de 1922, em que faltava a invenção de Sá-Carneiro ou o vanguardismo de Santa-Rita Pintor, além da falta de unidade esotérica dissolvida numa unidade eclética, com arranjos gráficos e paginações, conforme aponta António Quadros (2000, p. 41).

\section{Cartas de um sincero fingidor: o discurso esotérico em questão}

Ao tratar da epistolografia de Fernando Pessoa, Crabbée Rocha referese a uma "discrição anglo-saxónica" em relação ao mundo íntimo do poeta, apenas visível nos desabafos a Armando Côrtes-Rodrigues e a Mário de Sá-Carneiro: "Não tornaremos a encontrar, nas cartas de Pessoa, acentos de idêntica espontaneidade e entrega" (1965, p. 404). As crises do poeta e seus desassossegos apenas se revelam a seres de eleição. Na carta de 6 de dezembro de 1915, escrita a Mário de Sá-Carneiro, Fernando Pessoa comenta sobre uma das muitas de suas crises intelectuais:

A primeira parte da crise intelectual, já V. sabe o que é; a que apareceu agora deriva da circunstância de eu ter tomado conhecimento com as doutrinas filosóficas. 0 modo como as conheci foi, como V. sabe, banalíssimo. Tive de traduzir livros teosóficos. (PESSOA, 1999a, p. 184)

Ao traduzir as ideias contidas nos livros teosóficos, Fernando Pessoa sente-se atraído e atemorizado pelos mistérios da Teosofia, como se pode observar no trecho subsequente da carta:

Eu nada, absolutamente nada, conhecia do assunto. Agora, como é natural, conheço a essência do sistema. Abalou-me a um ponto que eu julgaria hoje impossível, tratando-se de qualquer sistema religioso. 0 caráter extraordinariamente vasto desta religião-teosofia; a noção de força, de domínio, de conhecimento superior e extra-humano que ressumam as obras teosóficas, perturbaram-me muito. (1999a, p. 184)

Os aspectos ressaltados por Pessoa como positivos da Teosofia referemse à força, ao domínio e ao conhecimento superior e transcendental. No entanto, o poeta sente-se perturbado pelo fato de estar adquirindo o conhecimento do mundo do ocultismo. Na mesma carta, Fernando Pessoa comenta: 
Ora, se V. meditar que a Teosofia é um sistema ultracristão, no sentido de conter os princípios cristãos elevados a um ponto onde se fundem não sei em que além-Deus, e pensar no que há de fundamentalmente incompatível com o meu paganismo essencial, V. terá o primeiro elemento grave que se acrescentou à minha crise. Se depois reparar que a Teosofia, porque admite todas as religiões, tem caráter inteiramente parecido com o paganismo, que também admite no seu panteão todos os deuses, V. terá o segundo elemento da minha grave crise de alma. A Teosofia apavora-me pelo seu mistério e pela sua grandeza ocultista, repugna-me pelo seu humanitarismo e apostolismo (V. compreende?) essenciais, atrai-me por se parecer tanto com um "paganismo transcendental" (é este o nome que eu dou ao modo de pensar a que havia chegado), repugna-me por se parecer tanto com o cristianismo, que não admito. (1999a, p. 184-185)

É possível afirmar que a crise resulta das relações comparativas que Fernando Pessoa tenta estabelecer entre a Teosofia e os demais sistemas filosóficos e religiosos, o que lhe causa sentimentos ambíguos de atração e repulsão pelas doutrinas teosóficas, como bem resume na seguinte passagem da carta: "É o horror e a atração do abismo realizados no alémalma. Um pavor metafísico, meu querido Sá-Carneiro!” (1999a, p. 184-185). Acerca dessa crise relatada na carta a Mário de Sá-Carneiro, Murillo Nunes de Azevedo comenta:

Fernando Pessoa penetrou fundo nas doutrinas que lhe proporcionavam felicidade, mas ao mesmo tempo um sofrimento profundo. 0 poeta, o místico, o profeta, mergulhava fundo no além-mundo. Todo seu ser sensível, ao vibrar com o esforço, produzia. Neste momento ele inveja o homem comum, que vive como animal, come, procria, sem essas preocupações. Mas, no fundo sabe que é um escolhido. (1972, p. xxx)

Os trechos da carta transcritos anteriormente remetem a outras três importantes cartas: uma sobre a "crise de incompatibilidades", outra sobre o despertar da mediunidade de Pessoa e outra sobre a posição esotérica do poeta.
Quando Fernando Pessoa alude à primeira parte da sua crise intelectual, diz que Sá-Carneiro já sabe do que se trata. Acredito que Fernando Pessoa esteja referindo-se à crise de incompatibilidades exposta na já comentada carta de 19 de janeiro de 1915, escrita a Armando Côrtes-Rodrigues. Nessa carta, Fernando Pessoa revela sua missão espiritual como poeta e reflete sobre o processo de criação artística, particularmente a heteronímia. Também comenta sobre sua "crise de incompatibilidades", patriotismo e a necessidade de ascensão do ser humano através da arte. 0 poeta manifesta na carta seu desejo de se abrir com alguém, apesar de sua reserva natural. $\mathrm{E}$ acaba por estabelecer a relação interdiscursiva entre o processo de criação artística com o discurso esotérico.

De modo que, à minha sensibilidade cada vez mais profunda, e à minha consciência cada vez maior da terrível e religiosa missão que todo o homem de génio recebe de Deus com o seu génio, tudo quanto é futilidade literária, mera-arte, vai gradualmente soando cada vez mais a oco e a repugnante. Pouco a pouco, mas seguramente, no divino cumprimento íntimo de uma evolução cujos fins me são ocultos, tenho vindo erguendo os meus propósitos e as minhas ambições cada vez mais à altura daquelas qualidades que recebi [...] E, assim, fazer arte parece-me cada vez mais importante coisa, mais terrível missão - dever a cumprir arduamente, monasticamente, sem desviar os olhos do fim criador-de-civilização de toda a obra artística. E por isso o meu próprio conceito puramente estético da arte subiu e dificultou-se; exijo agora de mim muita mais perfeição e elaboração cuidada. (1999a, p. 142-143)

Fernando Pessoa comenta sobre a dificuldade de cumprimento da sua "terrível e religiosa missão", relacionada a uma arte sincera, não mais relacionada à atitude de blague, ou de épater les bourgeois, que tanto caracterizaram a produção literária de alguns dos seus companheiros de geração. Pessoa entende por atitude de blague os poemas e manifestos relacionados ao discurso vanguardista do Paulismo e do Interseccionismo: " $\mathrm{E}$ por isso não são sérios os Paúis, nem seria o Manifesto interseccionista de que 
uma vez lhe li trechos desconexos. Em qualquer destas composições a minha atitude para com o público é de um palhaço" (1999a, p. 144-145). Embora se possa perceber uma busca de um Além, Pessoa entende essas produções literárias como textos insinceros, pelo objetivo primeiro de pasmar um público burguês, acostumado com discurso positivista e racionalista.

Para Pessoa, o discurso vanguardista relaciona-se à insinceridade, pois “[...] não contêm uma fundamental ideia metafísica, isto é, por onde não passa, ainda que como um vento, uma noção da gravidade e do mistério da vida" (1999a, p. 144). É por isso que Pessoa considera sincero o discurso dos heterônimos, ainda que "sentido na pessoa de outro; é escrito dramaticamente, mas é sincero (no meu grave sentido da palavra) como é sincero tudo o que diz o Rei Lear, que não é Shakespeare, mas uma criação dele" (1999a, p. 144 - grifos do autor).

Cada vez mais convencido de sua missão espiritual de "criador-decivilização de toda a obra artística” (1999a, p. 143), o poeta-profeta, que já anunciara a vinda do Supra-Camões, aquando da sua atuação na Revista $A$ Águia, antes da viagem pelo projeto de Orpheu, apresenta um ideal patriótico presente no seu discurso literário: “[...] e não penso em fazer arte que não medite fazê-lo para erguer alto o nome português através do que eu consiga realizar" (1999a, p. 143).

A fortuna crítica sobre as relações entre o discurso literário pessoano e o discurso esotérico é abundante (apesar de haver quem discorde desse tipo de hermenêutica) e já gerou bons frutos, em ensaios de Yvette Centeno, Georg Rudolf Lind, António Quadros, Dalila Pereira da Costa, Elêusis Camocardi, João Alves das Neves, Pedro Teixeira da Mota, dentre outros importantes críticos literários. Para ficar com apenas um exemplo significativo que autoriza essa abordagem das relações interdiscursivas (esoterismo e poesia), convém citar um ensaio de Eduardo Lourenço, escrito em 1973 e republicado no livro Fernando Pessoa revisitado. Trata-se de "A existência mítica ou a porta aberta". Ao analisar poemas ocultistas de Pessoa, Lourenço faz afirmações contundentes: "A poesia ocultista cobre o espaço inteiro da vida e da obra de Pessoa" (1981, p. 175); "Não há em toda a poesia de Fernando Pessoa nada mais afirmativo que a pulsão ocultista” (1981, p. 176 - grifos do autor); "A visão ocultista permite a Pessoa integrar positivamente o obstáculo des-realizante por excelência, a Morte, [...] como transparência suprema e supremo repouso" (1981, p. 177).

A pulsão ocultista, por mais que seja abundante no discurso poético do ortônimo, também se faz presente, elaborada de distintas maneiras, na produção literária de outros heterônimos. Em carta de 19 de janeiro de 1915, ao companheiro de Orpheu Armando Côrtes Rodrigues (1891-1971), Fernando Pessoa salienta que, por mais que os heterônimos se diferenciem entre si, em todos há uma preocupação com o mistério de existir: "Por isso é sério tudo o que escrevi sob os nomes de Caeiro, Reis, Álvaro de Campos. Em qualquer destes pus um profundo conceito da vida, diverso em todos três, mas em todos gravemente atento à importância misteriosa de existir" (1999a, p. 144).

Nessa carta a Armando Côrtes-Rodrigues, Fernando Pessoa denomina sua crise psíquica de "crise de incompatibilidade": "Esta incompatibilidade é sentida por mim, dentro de mim, e é comigo que está o peso todo da minha divergência de aqueles que me cercam" (1999a, p. 142). A crise de incompatibilidades resulta de alguns fatores apontados por Mário Sacramento em seu livro Fernando Pessoa: poeta da hora absurda. Segundo o crítico, o fato de, no momento da elaboração do discurso epistolar, Fernando Pessoa estar vivendo só, devido à ausência de seus parentes, agrava o estado de espírito do poeta. Sacramento analisa três fatos na carta: 1) a crise psíquica seria pouco nítida sem suas causas, 2) Fernando Pessoa apresenta uma certa resistência em admitir que o isolamento da família agravava os seus problemas, 3) o poeta revela que tinha vontade de falar da sua 
psicologia (1970, p. 43). O interlocutor desejado, nesse momento de crise, deveria apresentar duas condições interligadas: ser, ao mesmo tempo, um espírito religioso e literário.

Antes de discutir acerca da posição esotérica de Fernando Pessoa, considero relevante apresentar uma manifestação dos conflitos intelectuais resultantes de seu envolvimento com o ocultismo. Em carta de 24 de junho de 1916 a Ana Luísa Nogueira, a tia Anica, Fernando Pessoa revela o despertar da sua mediunidade:

Aí por fins de Março (se não me engano) comecei a ser médium. Imagine! $\mathrm{Eu}$, que (como deve recordar-se) era um elemento atrasador nas sessões semiespíritas que fazíamos, comecei, de repente, com a escrita automática. Estava uma vez em casa, de noite, tendo vindo da Brasileira, quando senti a vontade de, literalmente, pegar numa pena e pô-la sobre o papel. É claro que depois é que dei por o facto de que tinha sido um impulso. (PESSOA, 1999a, p. 216)

Além da descrição detalhada da escrita automática, dos sinais cabalísticos e maçônicos que o perturbam e que provam a legitimidade da sua mediunidade, Fernando Pessoa relata a sua tia outros fenômenos que lhe têm ocorrido, como a sensibilidade intuitiva, a visão astral e a visão etérica, o magnetismo e o desaparecimento de seu rosto diante do espelho.

A sensibilidade intuitiva começou a ser despertada no espírito de Fernando Pessoa na ocasião do suicídio de Sá-Carneiro:

Quando o Sá-Carneiro atravessava em Paris a grande crise mental, que o havia de levar ao suicídio, eu senti a crise aqui, caiu sobre mim uma súbita depressão, vinda do exterior, que eu, ao momento, não consegui explicar-me. Essa forma de sensibilidade não tem tido continuação. (1999a, p. 219 - grifos do autor)

Sobre a visão astral, Fernando Pessoa assim a descreve:
A 'visão astral' está muito imperfeita. Mas, às vezes, de noite, fecho os olhos e há uma sucessão de pequenos quadros, muito rápidos, muito nítidos (tão nítidos como qualquer coisa do mundo exterior). Há figuras estranhas, desenhos, sinais simbólicos, números (também já tenho visto números), etc. (1999a, p. 219)

Sobre a visão etérica, ou a visão da aura das pessoas, Fernando Pessoa comenta:

Há momentos, por exemplo, em que tenho perfeitamente alvoradas de 'visão etérica' - em que vejo a 'aura magnética' de algumas pessoas, e, sobretudo, a minha ao espelho e, no escuro, irradiando-me das mãos. Não é alucinação porque o que eu vejo outros veem-no, pelo menos, um outro, com qualidades destas mais desenvolvidas. Cheguei, num momento feliz de visão etérica, a ver, na Brasileira do Rossio, de manhã, as costelas de um indivíduo através do fato e da pele. Isto é que é a visão etérica no seu pleno grau. (1999a, p. 219 - grifos do autor)

Pessoa comenta sobre os graus de visão etérica e chega a mencionar haver visto sua própria aura magnética no espelho, irradiando das mãos. Em outro trecho da mesma carta, afirma sobre o desaparecimento de seu rosto diante do espelho e o surgimento de outros rostos:

Há mais curiosidade do que susto, ainda que haja às vezes coisas que metem um certo respeito, como quando, várias vezes, olhando para o espelho, a minha cara desaparece e me surge um fácies de homem de barbas, ou um outro qualquer (são quatro, ao todo, os que assim me aparecem) (1999a, p. 220)

No fenômeno descrito, é possível perceber a tendência de Fernando Pessoa para o desdobramento, próximo da heteronímia. Segundo o Dicionário de símbolos, de Jean Chevalier e Alain Gheerbrant, o espelho reflete a verdade, a sinceridade, o conteúdo do coração e da consciência e fornece 
uma imagem invertida da realidade exterior (2001, p. 393-394). Como visto anteriormente, na carta escrita a Côrtes-Rodrigues, Fernando Pessoa aponta como sinceros o aparecimento e a escrita dos heterônimos, pois se trata de algo "sentido na pessoa de outro" (1999a, p. 144 - grifos do autor). Trata-se, pois, de um desdobramento de personalidade, que se projeta, muitas vezes, em fenômenos nos quais entra em jogo a percepção visual, como a sombra e o espelho. 0 filósofo francês Clément Rosset relaciona o espelho com o desdobramento da personalidade.

É por isso que a busca do eu, especialmente nas perturbações de desdobramento, está sempre ligada a uma espécie de retorno obstinado ao espelho e a tudo o que pode apresentar uma analogia com o espelho: assim, a obsessão da simetria sob todas as suas formas, que repete à sua maneira a impossibilidade de jamais restituir esta coisa invisível que se tenta ver, e que seria o eu diretamente, ou um outro eu, seu duplo exato. (1998, p. 80)

Antes de concluir a carta à Tia Anica, Fernando Pessoa revela-lhe os efeitos que os conhecimentos esotéricos têm lhe causado: sofrimento, desgosto, isolamento, abandono e amargura:

Já sei o bastante das ciências ocultas para reconhecer que estão sendo acordados em mim os sentidos chamados superiores para um fim qualquer que o Mestre desconhecido, que assim me vai iniciando, ao impor-me essa existência superior, me vai dar um sofrimento muito maior do que até aqui tenho tido, e aquele desgosto profundo de tudo que vem com a aquisição destas altas faculdades. Além disso, já o próprio alvorecer dessas faculdades é acompanhado duma misteriosa sensação de isolamento e de abandono que enche de amargura até ao fundo da alma. (1999a, p. 220)

O espiritismo foi passageiro na vida do poeta. Seu maior interesse deuse pela Teosofia, diferente do espiritismo no tocante às comunicações com as entidades. Em uma "nota do tradutor", no livro Conferências teosóficas, de Annie Besant (cf. SIMÕES, 1950, p. 544-545), Fernando Pessoa explica que o espiritismo e a Teosofia, apesar de terem a mesma finalidade de conceber racionalmente a vida futura, diferem-se no tocante à comunicação com as entidades. A teosofia considera as comunicações espíritas prejudiciais tanto aos habitantes do plano astral como os do plano físico. Para os primeiros, resultaria em intensificações de suas paixões, seus sonhos e seus desejos inferiores, pelo fato de voltarem sua atenção para a vida terrestre. Para os últimos, resultaria em perturbações orgânicas e psíquicas, podendo levar à loucura. Para as comunicações com entidades, os teósofos não recorrem a intermediários (médiuns), para receberem em seus corpos os espíritos, mas se utilizam de sua própria natureza espiritual para entrarem em contato com as entidades.

Gaspar Simões, na sua biografia sobre Fernando Pessoa, afirma que a Teosofia entra na vida do poeta desde a apoplexia que vitima sua mãe, D. Madalena Nogueira, e dura até a morte dela em 1925. A ligação afetiva com a mãe era tão forte que Pessoa sofreu muito a morte dela, rejeitando o princípio teosófico da ascendência. Acerca do abalo sofrido por Pessoa, sustenta Gaspar Simões:

Se a teosofia lhe ensinava que a morte não existe, pois cada homem que vive na terra do céu desceu e se à vida desce é apenas para de novo voltar à verdadeira morada de onde temporariamente se afastou [...] 0 certo é que o abalo nele produzido pelo desaparecimento daquela que era o seu único ponto de ligação com a própria terra foi tão profundo que o mesmo edifício teosófico se sentiu abalado nos seus alicerces. (1950, p. 540)

Depois da fase espírita e da fase teosófica, Pessoa dedicou-se mais ao ocultismo, que seria para ele a verdadeira forma da iniciação esotérica que tanto buscava. Há de se destacar que, mesmo no período do espiritismo, relatado em carta à Tia Anica, o autor de Mensagem menciona as "ciências ocultas", e refere-se novamente a uma missão que "o Mestre desconhecido [...] me vai iniciando", como se encontra também em uma das cartas a 
Côrtes-Rodrigues, discutida anteriormente. "Ocultismo" é análogo ao conceito de "esoterismo", uma vez que uma atividade esotérica se caracteriza por ser secreta, oculta. Com relação à diferença entre "exoterismo" e "esoterismo", assim se posiciona Fernando Pessoa, em um fragmento do espólio:

[...] segue que se pensou que esses ensinamentos se deveriam dividir em duas ordens: exotericos ou profanos os que são expostos de modo que a todos possam ser ministrados; esotericos ou occultos os que, sendo mais verdadeiros, ou inteiramente verdadeiros, não convém que se ministrem senão a indivíduos previamente preparados, gradualmente preparados, para os receber. A esta preparação se chamava, e chama, iniciação. (Esp. 54-97 apud CENTENO, 1985a, p. 45)

Acerca do ocultismo, o poeta descreve três caminhos para a busca das verdades ocultas do cosmos. $\mathrm{O}$ ocultismo (ou esoterismo) seria a busca do lado interno das coisas e se realizaria através de três caminhos: o místico, o mágico e o alquímico. Acerca desses três caminhos, esclarece Fernando Pessoa em um fragmento do espólio:

Seja como for, o certo é que os ensinamentos ministrados nos mysterios abrangem três ordens de coisas: 1) a verdadeira natureza da alma humana, da vida e da morte, 2) a verdadeira maneira de entrar em contacto com as forças secretas da natureza e manipulá-las, e 3) a verdadeira natureza de Deus e dos Deuses e da creação do mundo. São, respectivamente, o segredo alchimico, o segredo magico e o segredo mystico. (Esp. 54-97 apud CENTENO, 1985a, p. 45-46)

Apesar de os três caminhos acima descritos apresentarem o adjetivo "verdadeiro", a escolha do poeta é feita em relação ao caminho alquímico. O caminho místico revela-se lento, enquanto o mágico seria perigoso por envolver práticas como bruxaria. Já o caminho alquímico seria o mais perfeito de todos, pois envolve a transmutação da própria personalidade humana. Assim, da mesma forma que se acreditava que seria possível transformar qualquer metal em ouro, também se podia transmutar a própria personalidade.

Pessoa sempre foi muito atento aos estudos esotéricos, como se pode perceber em suas cartas e em seus poemas. Numa das últimas cartas escritas antes de seu falecimento, em 13 de janeiro de 1935, responde a Adolfo Casais Monteiro:

Quanto à 'iniciação' ou não, posso dizer-lhe só isto, que não sei se responde à sua pergunta: não pertenço a Ordem Iniciática nenhuma. A citação, epígrafe ao meu poema 'Eros e Psyche', de um trecho (traduzido, pois o Ritual é em latim) do Ritual do Terceiro Grau da Ordem Templária de Portugal, indica simplesmente - o que é facto - que me foi permitido folhear os Rituais dos três primeiros graus dessa Ordem, extinta, ou em dormência, desde cerca de 1888. Se não estivesse em dormência, eu não citaria o trecho do ritual, pois se não devem citar (indicando a origem) trechos de Rituais que estão em trabalho. (PESSOA, 1999b, p. 347)

Por este trecho, além da fidelidade que Fernando Pessoa manifesta em relação aos ensinamentos da Ordem dos Templários, o poeta não se reconhece iniciado. No entanto, Yvette Centeno encontrou, entre os documentos pessoais do poeta, datado também de 1935, a seguinte declaração

Posição religiosa: ... Fiel, por motivos que mais adiante estão implícitos, à Tradição secreta do Christianismo, que tem íntimas relações com a Tradição Secreta em Israel (a Santa Kabbalah) e com a essência oculta da Maçonaria. Posição iniciática: Iniciado, por comunicação directa de Mestre a Discípulo, nos três graus menores da (aparentemente extinta) Ordem Templária de Portugal. (Esp. 54-6 apud CENTENO, 1985b, p. 69-70)

É possível estabelecer aqui um confronto entre dois discursos do próprio Fernando Pessoa. $\mathrm{O}$ segundo discurso nega o primeiro à medida que seu enunciador revela ser um iniciado, o que não fizera no anterior. Ao analisar 
atenciosamente o primeiro discurso, é possível perceber o enunciador preocupado com o que tem a dizer. Basta lembrar que ele diz "posso dizer-lhe só isto", o que me leva a conjeturar haver outras questões não mencionadas, relacionadas ao plano do segredo.

Considera-se, pois, como inerente à condição da carta o ela ser secreta, ou até confidencial. A coberto deste sigilo, a carta, dirigida a um ser eleito, a um alter ego digno da confiança que se deposita nele, usa duma maior franqueza. Essa sinceridade característica só conhece duas limitações essenciais: o receio da violação e a prudência ditada pelo velho preceito do scripta manent. (ROCHA, 1965, p. 21)

A carta em que Fernando Pessoa afirma não pertencer a nenhuma ordem iniciática foi escrita em 1935, período marcado pela ditadura salazarista, de extrema direita e repressora das ordens secretas em Portugal. Fernando Pessoa jamais poderia declarar-se iniciado em uma carta, mesmo sendo o enunciatário dela um amigo como Adolfo Casais Monteiro, uma vez que em períodos ditatoriais, o "receio da violação" e a "prudência" conferem estatuto de regras de sobrevivência. Por outro lado, como o segundo discurso pertence aos fragmentos do espólio, ou seja, eram documentos de estudos pessoais, Fernando Pessoa revela-se iniciado nos três graus menores da Ordem Templária de Portugal que, segundo ele, está "aparentemente extinta". Por aqui, nota-se que as atividades esotéricas não findaram, mas foram suspensas no decorrer da ditadura salazarista, para que seus membros não sofressem perseguições do governo.

\section{A "poesia intercalada" nas cartas e o "curioso fenômeno do desdobramento"}

No presente trabalho, não pretendo examinar provas da iniciação de Fernando Pessoa, mas considerar o valor estético dessas cartas, como textos que se aproximam da literatura e apresentam discursos esotéricos na sua base, tanto no conteúdo como na linguagem. Claro está que é possível, em se tratando de uma correspondência "vasta e variada", "acompanhar o artista da mocidade à velhice" (ROCHA, 1965, p. 25), e elaborando, no conjunto das imagens somadas, seu percurso biográfico, "seguindo, ao mesmo tempo em que as peripécias da sua existência e as feições salientes do seu carácter, a evolução das suas ideias, das suas doutrinas estéticas, das suas preocupações dominantes, etc." (1965, p. 25). Ao tratar do gênero epistolar, Crabbé Rocha aproxima-o do diário, da confissão, do romance, do relato de viagem e do teatro e salienta que

[...] se nos debruçarmos sobre os textos, deparamos como legítimas parcelas de descrição, de doutrina, de diálogo e, mesmo, ocasionalmente, de poesia intercalada - isto é, confundem-se, por momentos, com qualquer das formas literárias. (1965, p. 26; grifos meus)

Dessa forma, é possível encontrar na correspondência de Fernando Pessoa "poesia intercalada", texto escrito e/ou veiculado através da carta. A título de ilustração, considero o poema "Abdicação", escrito em 1 o de fevereiro de 1913, numa carta de Fernando Pessoa a Mário Beirão (1890-1965), um dos colaboradores da revista A Águia. Na carta, Fernando Pessoa, após comentar a solidão em que se encontra, relata a "crise de abundância" que vem passando, caracterizando-a como um estado na alma de rapidez ideativa, ou seja, um tumulto de ideias poéticas, filosóficas, críticas e metafísicas. "As ideias que perco causam-me uma tortura imensa, sobrevivem-me nessa tortura, escuramente outras" (1999a, p. 81). Acredito ser esse tumulto de ideias a força motriz da produção poética de Pessoa, principalmente nesses anos de 1912 a 1915, período de transição entre o saudosismo de A Águia e as irreverentes propostas de Orpheu. 


\section{Abdicação}

Toma-me, ó Noite Eterna, nos teus braços

E chama-me teu filho... Eu sou um Rei

Que voluntariamente abandonei

O meu trono de sonhos e cansaços.

Minha espada, pesada a braços lassos,

Em mãos viris e calmas entreguei,

E meu ceptro e coroa - eu os deixei

Na antecâmara, feitos em pedaços.

Minha cota de malha, tão inútil,

Minhas esporas dum tinir tão fútil -

Deixei-as pela fria escadaria.

Despi a Realeza, corpo e alma,

E regressei à Noite antiga e calma

Como a paisagem ao morrer do dia. (1999a, p. 82-83)

Acerca da espacialização do poema, pode-se dizer que há dois espaços fechados ("antecâmara" e "fria escadaria") e um espaço aberto ("paisagem ao morrer do dia"). Os espaços abertos simbolizam uma ascensão gradual do sujeito, do abandono do seu palácio, representado pela "antecâmara" e pelos objetos ali deixados (cetro e coroa), até a travessia pelo caminho alquímico proposto, que em "Abdicação" é figurativizado pela escadaria que o leva do espaço fechado ao espaço aberto, onde ocorrerá o abandono total dos bens materiais: "Despi a Realeza, corpo e alma”. A disjunção do sujeito com a materialidade levá-lo-á à morte física, representada pela imagem crepuscular do último verso, e ao encontro transcendental com o mundo espiritual, representado pela "Noite antiga" do penúltimo verso.

As imagens crepusculares anunciam a vinda da noite, presente tanto no início como no final do poema, de forma circular, o que remete para a teoria das reminiscências de Platão. Como se sabe, Platão concebia a existência de dois mundos: o mundo sensível (material) e o mundo inteligível (espiritual). 0 filósofo Clément Rosset relaciona a teoria da reminiscência de Platão, presente no mito da caverna, com a teoria do duplo: "A verdade do platonismo permanece então realmente ligada ao mito da caverna: este real-aqui é o inverso do mundo real, sua sombra, seu duplo. E os acontecimentos do mundo são apenas réplicas dos acontecimentos reais" (1998, p. 53)

Segundo a filosofia platônica, o mundo inteligível seria, pois, o duplo do mundo sensível. Em "Abdicação", a "Noite Eterna" da primeira estrofe, também chamada de "Noite antiga", representaria o universo duplicado, o mundo inteligível para o qual o sujeito deseja voltar e reencontrar as ideias originais. 0 crepúsculo, que aparece no poema no verso "Como a paisagem ao morrer do dia", simbolizaria a morte do sujeito e sua reintegração no mundo espiritual ou inteligível: "E regressei à noite antiga e calma". A noite antiga, além de se referir à "Noite Eterna" da primeira estrofe do poema, é acompanhada do adjetivo "calma" presente na "tristeza suave, calma" do trecho da carta citado anteriormente, simbolizando a suave travessia do sujeito pelas escadarias e o abandono dos bens materiais. E de fato, como bem assinala Pessoa na carta, "o soneto não é só calmo, mas também mais ligado e conexo que algumas coisas que eu tenho escrito" (1999a, p. 82).

Assim, as relações de sentido da poética pessoana podem ser estabelecidas a partir do confronto do discurso esotérico da carta com o discurso esotérico do poema. Tanto no discurso poético como no epistolar, faz-se presente o processo de desdobramento: "O fenômeno curioso do desdobramento é coisa que habitualmente tenho, mas nunca o tinha sentido neste grau de intensidade" (1999a, p. 82). O fenômeno descrito apresenta-se poetizado em "Abdicação" na forma de um desdobramento espacial, pois o sujeito percorre o mundo sensível, onde abandona os bens materiais. É, pois, seu intuito integrar-se ao mundo inteligível, em que as verdades insondáveis do universo podem ser compreendidas. 
As preocupações acerca do espiritismo, da teosofia e do esoterismo percorrem parte da produção epistolar de Fernando Pessoa, com vasta leitura de obras, muitas das quais solicitadas a destinatários de suas cartas, como escritos teosóficos, sebastianistas e rosacrucianos. A constante elaboração de um discurso poético em torno do discurso esotérico parece desaguar no ano de 1932, pois, conforme Dalila Pereira da Costa, “[...] 1932 será por certo o ano crucial, aquele onde se revela mais nítida e dramaticamente a sua procura através das correntes esotéricas" (1996, p. 58). Em 1932, o “ano crucial", e prosseguindo até o ano da morte de Fernando Pessoa, abundam produções literárias do ortônimo, como se o poeta estivesse à procura de um caminho que lhe permitisse a unificação dos opostos, tal como entendido na alquimia. Datam de 1932 importantes poemas como "Iniciação", "Eros e Psique" e "Monte Abiegno".

Neles surgem os mesmos temas que toda a vida acompanharam o poeta: preexistência, conhecimento por reminiscência, vida terrestre como exílio, eu terrestre como sombra doutro que vive na eternidade, esta vida como um estado de sono, a procura da alma, ou do anjo [...]. (COSTA, 1996, p. 58-9)

Segundo Yvette Centeno, a alquimia refere-se, pois, à conjunção e à unificação de elementos opostos. A autora discorda de opiniões clássicas nos estudos pessoanos de João Gaspar Simões e Georg Rudolf Lind que homologam o caminho alquímico do poeta com sua fragmentação heteronímica. Ao contrário desses dois críticos, Centeno afirma que “[...] esse desdobramento representa uma fragmentação dolorosa, e que ainda em 'Chuva Oblíqua' ele [Pessoa] pretendeu consciente e inconscientemente combater" (1976, p. 83). A heteronímia foi, pois, um procedimento literário que o poeta encontrou para expressar a multiplicidade de sensações e a fragmentação dolorosa. Dessa forma, enquanto nas décadas de 1910 e 1920 se encontram muitos poemas dos heterônimos, percebe-se, sobretudo nos anos posteriores a
1932, uma proliferação de poemas do ortônimo relacionados a uma estética da abdicação como possibilidade de reencontro da unidade perdida.

\section{Considerações finais}

Do material epistolográfico de Fernando Pessoa, destacam-se as três edições preparadas por Manuela Parreira da Silva: Correspondência (19051922), Correspondência (1923-1935) e Correspondência inédita, esse último volume com prefácio de Teresa Rita Lopes. Para o presente artigo, optei por um recorte temporal de 1913 a 1917, anos de grande efervescência cultural em torno das revistas A Águia (1912), Orpheu (1915), Centauro (1916) e Portugal Futurista (1917).

Destaquei, na segunda parte do artigo, principalmente o ano de 1915, em torno das reflexões sobre a necessidade de uma intervenção cultural no acanhado meio lisboeta, por meio do projeto e da concretização desse "ideal esotérico" que constitui a Orpheu, síntese de todos os movimentos modernos, como afirma Pessoa. Nesse ano crucial da explosão heteronímica pessoana e das várias estéticas que constituem os Ismos da geração de Orpheu, alargamse os destinatários, figurando Santa-Rita Pintor, Ronald de Carvalho, Camilo Pessanha, Miguel de Unamuno, editores ingleses e jornais portugueses. Aparece, nesse contexto de entusiasmo febril, como enunciador de duas importantes cartas acerca da recepção crítica da Orpheu, o engenheiro sensacionista Álvaro de Campos, que assina essas duas cartas estudadas.

Nos meses anteriores ao aparecimento do primeiro número da Orpheu, e também nos meses posteriores à publicação do segundo número da "revista trimestral de literatura”, encontra-se um Fernando Pessoa inquieto e desejoso de confidenciar suas crises intelectuais e esotéricas, como fica patente nas cartas de 19 de janeiro de 1915 a Côrtes-Rodrigues e de 6 de dezembro do mesmo ano a Sá-Carneiro. Data de 24 de junho de 1916 a missiva endereça 
a Ana Luísa Nogueira, a Tia Anica, acerca do despertar da mediunidade do poeta. E durante os anos subsequentes, encontrar-se-ão cartas referentes a horóscopos, encomendas de livros esotéricos e sebastianistas, terapêutica magnética, dentre outros temas relacionados ao ocultismo.

De 1927 até 1935, encontram-se cartas a destinatários da Revista Presença, como José Régio, Branquinho da Fonseca, João Gaspar Simões e Adolfo Casais Monteiro. Nessas últimas cartas, aparecem vários projetos editoriais de obras suas e de Mário de Sá-Carneiro, pois, como é sabido, os presencistas foram os principais divulgadores da obra dos escritores de Orpheu. Nessas cartas, ao contrário daquelas escritas nos anos febris de Orpheu e endereçadas a amigos que partilhavam seu universo íntimo, o discurso epistolar carrega-se de uma "meditada elaboração, aliás legítima e de acordo com a maturidade do poeta, que tende para a fixação intelectualizada do mito Pessoa"(ROCHA, 1965, p. 404). É precisamente dessa época o poema "Autopsicografia", publicado em 1932 na revista Presença, no qual o poeta se declara um "fingidor". Tem-se, nesse período, o contrário das confissões sinceras a amigos como Armando Côrtes-Rodrigues e Mário de Sá-Carneiro. Para este último, escreveu e copiou a carta de 14 de março de 1916, na qual enfatiza a "sinceridade com que a escrevo" (1999a, p. 211). Em outro passo da carta, destaca sua cota de sinceridade apenas para os mais íntimos: "Se eu não estivesse escrevendo a você, teria que lhe jurar que esta carta é sincera, e que as coisas de nexo histérico que aí vão saíram espontâneas do que sinto" (1999a, p. 211).

É necessário, pois, examinar com cuidado as cartas de Fernando Pessoa. Dalila Pereira da Costa reforça a necessidade de se estudar a produção poética de Fernando Pessoa a partir do discurso ensaístico do autor em seus fragmentos em prosa, que no caso do presente trabalho, pode referirse ao gênero epistolar, pelo fato de nas cartas o poeta apresentar "opiniões totalmente conscientes e intelectualizadas":
As opiniões totalmente conscientes e intelectualizadas na sua obra em prosa, nunca estarão em contradição com as criações da imaginação: mas estas serão como o seu aprofundamento, porque atingidas a um nível de realidade infinitamente mais rico, inesgotável. (1996, p. 46)

A citação vem ao encontro do processo hermenêutico que utilizo para estabelecer as relações interdiscursivas presentes no discurso esotérico de Pessoa em cartas e no discurso literário de seus poemas. Faz-se necessário, pois, examinar a produção poética de Fernando Pessoa em relação à sua produção epistolar, já que, como afirmei, nas cartas o poeta explicita aspectos que nos poemas ficam subjacentes a uma linguagem repleta de símbolos. Se boa parte das cartas de Fernando Pessoa apresenta um discurso ensaístico, próximo do discurso filosófico, é possível, pelo estudo da correspondência do autor, esclarecer alguns aspectos da linguagem hermética utilizada em muitos de seus poemas.

\section{Referências}

ADORNO, Theodor. El ensayo como forma. In:__. Notas sobre literatura. Trad. Alfredo Brotons Muñoz. Madrid: Akal ediciones, 2003. p. 11-34. (Obra completa, 11).

AZEVEDO, Murillo Nunes de. Fernando Pessoa - o teósofo. In: BLAVATSKY, Helena. A voz do silêncio. 2. ed. Rio de Janeiro: Civilização Brasileira, 1969. p. ix-xxxviii.

CANDIDO, Antonio. Literatura e sociedade: estudos de teoria e história literária. 3. ed São Paulo: Nacional, 1973.

CASAS, Arturo. Breve propedéutica para el análisis del ensayo. In: ÁLVAREZ, Rosario; VILAVEDRA, Dolores. Cinguidos por unha arela común. Homenaxe ó Profesor Xesús Alonso Montero. Santiago de Compostela: Universidade de Santiago de Compostela: 1999. p. 1-15. CENTENO, Yvette. Fernando Pessoa e a filosofia hermética: fragmentos do espólio. Lisboa: Presença, 1985a.

CENTENO, Yvette. Fernando Pessoa. O amor. A morte. A iniciação. Lisboa: A Regra do Jogo, 1985b.

CENTENO, Yvette. Fragmentação e totalidade em "Chuva Oblíqua". In:

5 Aproximações. Lisboa: Ática, 1976. p. 71-92. 
CHEVALIER, Jean; GHEERBRANT, Alain. Dicionário de Símbolos. 16. ed. (Coord. Carlos Sussekind). Tradução Vera da Costa e Silva e outros. Rio de Janeiro: José Olympio, 2001.

COSTA, Dalila Pereira da. O esoterismo de Fernando Pessoa. 4. ed. Porto: Lello \& Irmão, 1996.

DOMÍNGUEZ, Pedro J. Chamizo. "Verdad y futuro: el ensayo como versión moderna del diálogo filosófico". In: ÁLVAREZ, Rosario; VILAVEDRA, Dolores. Cinguidos por unha arela común. Homenaxe ó Profesor Xesús Alonso Montero. Santiago de Compostela: Universidade de Santiago de Compostela: 1999. p. 16-42.

LIND, Georg Rudolf. Estudos sobre Fernando Pessoa. Lisboa: Imprensa Nacional-Casa da Moeda, 1981.

LOURENÇO, Eduardo. A existência mítica ou a porta aberta. In:

Fernando Pessoa revisitado: leitura estruturante do drama em gente. 2. ed. Lisboa: Moraes, 1981. p. 169-183.

MOISÉS, Massaud. História da literatura brasileira. Simbolismo. São Paulo: Cultrix, Edusp, 1984. v. 3.

ORPHEU: Revista trimestral de literatura. Lisboa: Ática, 1971. v. 1.

PESSOA, Fernando. Correspondência: 1905-1922. (Org. Manuela Parreira da Silva). São Paulo: Cia. Letras, 1999a.

PESSOA, Fernando. Correspondência: 1923-1935. (Org. Manuela Parreira da Silva). Lisboa: Assírio \& Alvim, 1999b. (Obras de Fernando Pessoa, 7).

QUADRoS, António. Fernando Pessoa. Vida, personalidade e gênio. 5. ed. Lisboa: Dom Quixote, 2000.

ROCHA, Andrée Crabbé. A epistolografia em Portugal. Coimbra: Almedina, 1965.

ROSSET, Clément. O real e seu duplo: ensaio sobre a ilusão. Apres. e Trad. José Thomaz Brum. Porto Alegre: L\&PM, 1998.

SACRAMENTO, Mário. Fernando Pessoa, poeta da hora absurda. 2. ed. Porto: Inova, 1970. SIMÕES, João Gaspar. Vida e obra de Fernando Pessoa: história de uma geração. Lisboa: Bertrand, 1950.

VILA MAIOR, Dionísio. Introdução ao modernismo. Coimbra: Almedina, 1996. 